\title{
Quantifying OHIP in the Context with Oral Health Literacy in Rural and Urban Population
}

\author{
Rahul N Gaikwad
}

\begin{abstract}
Aim: The present study was undertaken to assess the knowledge and awareness of oral health literacy among rural and urban people and to correlate it with the oral health-related quality of life (OHRQoL).

Materials and methods: The present study was conducted among the rural and urban population visiting the outpatient department. The study questionnaire was used to assess oral health literacy and these questions were framed based on the various aspects like general demographics, dental visit, and dentition status. A validated questionnaire to record the oral health impact profile (OHIP) was used to assess the quality of life. Further, the rapid estimate of adult literacy in dentistry-30 (REALD-30), the word recognition test, was used to assess oral health literacy. Results: Out of 1,000 participants, 500 were from the urban population and 500 from a rural area. The mean age of participants in the rural and urban population was $32.22 \pm 10.66$ and $30.43 \pm 10.3$, respectively. The mean score of OHIP in rural and urban participants was found to be $6.46 \pm 6.815$ and $6.34 \pm 8.492$, respectively. The mean score of REALD-30 in rural and urban participants was found to be $12.88 \pm 7.214$ and $20.9 \pm 7.334$, respectively.
\end{abstract}

Conclusion: Results suggest that dental health literacy have an independent effect on dental health outcomes.

Keywords: Dental health literacy, OHIP, Oral health literacy, REALD-30.

The Journal of Contemporary Dental Practice (2019): 10.5005/jp-journals-10024-2606

\section{INTRODUCTION}

Health literacy is defined as "the degree to which individuals have the capacity to acquire, process, and understand basic health information and services needed to make appropriate health decisions." ${ }^{\prime 1}$ In the health profession, the major skill that is required to master to be a good physician is the communication skill. ${ }^{2}$ Even though after mastering this skill, majority of the patients failed to apprehend what a medical doctor wants to communicate with them. ${ }^{3}$ Moreover, the current healthcare system is more multifaceted and demands patients to go through a complex process to find the right health care option and health information. This creates many challenges to less educated or low health literacy people to reap the advantage of available services and information. ${ }^{4}$ There are various examples quoted in the literature regarding the effect of low literacy on health care outcomes. Low health care literacy is so vulnerable to misinterpretation and misunderstanding which might lead to devastating effect at times. ${ }^{5}$

The National Adult Literacy Survey conducted in 1992 estimates that 40-44 million American adults lack basic health literacy and an additional 50 million have limited literacy skills. ${ }^{6}$ It has been noted in the literature that individuals with limited oral health literacy encounter numerous difficulties navigating to the right oral health care department. ${ }^{7}$ It was reported that a person with low oral health literacy, one's limited capacity to obtain, comprehend, and act on health information, is described as "the silent health epidemic." ${ }^{8}$

Various investigators around the world conducted research on the effect of health literacy on health outcome by using different instruments and methods to recognize a patient's oral health literacy skills. ${ }^{7,8}$ In literature, the patients' level of education was considered as a marker of health literacy, but it can be correctly correlated with the patient's reading skill rather than functional health literacy. This informal method can be further improved by additions of a few formal methods like reading and comprehension. ${ }^{9}$
Community Dentistry and Oral Epidemiology Department, College of Dentistry, Qassim University, Buraydah, Kingdom of Saudi Arabia

Corresponding Author: Rahul N Gaikwad, Community Dentistry and Oral Epidemiology Department, College of Dentistry, Qassim University, Buraydah, Kingdom of Saudi Arabia, Phone: +966 507124373, e-mail: dr.rahul.gaikwad@qudent.org

How to cite this article: Gaikwad RN. Quantifying OHIP in the Context with Oral Health Literacy in Rural and Urban Population. J Contemp Dent Pract 2019;20(7):834-837.

Source of support: Nil

Conflict of interest: None

In the context of health literacy, two literacy assessments are widely used, the rapid sstimate of adult literacy in medicine (REALM), a word recognition test, and the test of functional health literacy in adults (TOFHLA), a comprehension test. ${ }^{10}$ Similarly, for oral health literacy, the instruments published are The REALD-30, ${ }^{11}$ REALD-99, ${ }^{12}$ test of functional health literacy in dentistry (TOFHLiD), ${ }^{13}$ and oral health literacy instrument $(\mathrm{OHLI}) .^{9}$

A number of publications hypothesize that low dental health literacy can serve as a barrier to the use of information and result in poor oral health outcomes, particularly when combined with other risk factors. ${ }^{14-16}$ A study was done in India to assess the oral health literacy among the urban students but no such study was done to compare the oral health literacy among the rural and urban population. ${ }^{17}$ Therefore, the present study was undertaken to assess the knowledge and awareness of oral health literacy among rural and urban people and to correlate it with the OHRQoL.

\section{Materials and Methods}

A cross-sectional study was carried out among the urban and rural population of central India. The study was carried out at 
the Outpatient Department of Sharad Pawar Dental College and Hospital Sawangi (M), Wardha, Acharya Vinobha Bhave Research Hospital Sawangi (Meghe), Wardha, and VSPM Dental College, Hingana Road Digdoh Hill, Nagpur, Maharashtra, India. Before starting the study, ethical clearance was obtained from the Institutional Ethical Committee of Datta Meghe Institute of Medical Sciences, Sawangi (Meghe) Wardha and informed consent was taken from each participant. A pilot survey was carried out among 50 participants based on which a sample size of 1,000 was estimated by keeping the power of study $80 \%$ at $95 \%$ of the confidence interval. The participants who were included in the pilot study were excluded from the main study analysis. The participants who were literate included in the study should be between 18 and 80 years of age and should have studied Marathi and English as a language till the 12th standard. Participants with cognitive impairment vision or hearing problem and obvious signs of drug or alcohol intoxication were excluded.

In the present study, the study proforma was framed based on the various aspects like general demographics, information regarding dental visit, and dentition status. A disease-specific framework which included etiology anatomy and prevention and treatment categories to guide us in the selection of words in the development of REALD, where most commonly used 30 words were included to check the oral health literacy. These words were selected from the American Dental Association Glossary of Common Dental Terminology which were translated in Marathi by a native speaker and further validated by the translation and back translation method. Moreover, a validated questionnaire was adopted to record OHIP-14, which was first translated to the local language and further validated by the forward and back translation method. These questions were self-administered and close ended. The questionnaire formed from seven conceptually formulated dimensions that were based on Locker's theoretical model of oral health. ${ }^{18}$ The responses to these will be made on the Likert-type scale and coded 4 = "very often," 3 = "fairly often," 2 occasionally," I = "hardly ever," and O = "never."

In REALD-30, ${ }^{11}$ the word recognition test, participants were asked to read aloud the list of 30 words in REALD-30 by the investigator and scored based on the pronunciation. For each correct pronunciation, one score was awarded, and for each wrong pronunciation, zero score was recorded. The scores may range from 0 to 30 .

Since this study was performed in rural as well as urban areas, the words to be pronounced were translated in their respective intellectual language. Before the collection of the sample, the investigator was trained and calibrated at the Department of Public Health Dentistry, Sharad Pawar Dental College.

\section{Data Analysis}

For the statistical analysis of the data, the Statistical Package for the Social Sciences (SPSS), version 11.5 software package, was used. The Pearson product-moment correlation test was used to assess the test-retest reliability. The Mann-Whitney $U$ test was used to assess the significance of OHIP and REALD-30 among the study participants, whereas the proportion was calculated by using a Chi-square test and an intergroup comparison was carried out by using the $z$ test. The $p$ value $\leq 0.05$ was considered acceptable as a statistically significant.

\section{Results}

In the present study, out of 1,000 participants, 500 were from the urban population and 500 were from a rural area. The mean age of participants in rural and urban was $32.22 \pm 10.66$ and $30.43 \pm$ 10.38 , respectively. In total, from rural and urban, 600 participants were males and 400 were females (Table 1). A significantly greater proportion of rural participants at 2 years 112 (22.4\%) and 5 years 97 (19.4\%) visited a dentist than the urban counterpart. Whereas a majority of urban participants 222 (44.4\%) never visited dentist than rural participants 173 (34.6\%) and the difference was found to be statistically significant (Table 2). This could be the reason for significantly poor dentition status among urban participants 29 (5.8\%) than rural participants 15 (3.0\%) (Table 3).

The mean score of OHIP in the rural population $(6.46 \pm 6.81)$ was significantly high when compared with the urban population $(6.34 \pm 8.4)$. Whereas the mean score of REALD-30 was significantly low in the rural population $(12.88 \pm 7.214)$ compared with the urban population ( $20.9 \pm 7.334$ ) (Tables 4 and 6). To understand the correlation of oral health literacy with the study population and OHIP, the Pearson correlation coefficient test was used. It has been observed that the REALD-30 showed a significantly positive correlation with both populations, whereas it showed a negative correlation with OHIP and the difference was statistically significant $(r=-0.088 ; p 0.005)$ (Table 5). It can be inferred that the knowledge and awareness about the oral diseases and treatment option has an impact on OHRQoL and treatment outcome. A patient with low oral health literacy would not be able to understand different treatment options or underestimate the risk of the disease leading to an increase in the total burden of the oral diseases.

Table 1: Demographic distribution of study participants

\begin{tabular}{llll}
\hline \multicolumn{2}{l}{ Study participants } & Rural & Urban \\
\hline Age & & $32.22 \pm 10.66$ & $30.43 \pm 10.38$ \\
Sex & Male & $300(60.0 \%)$ & $300(60.0 \%)$ \\
& Female & $200(40.0 \%)$ & $200(40.0 \%)$ \\
\hline
\end{tabular}

Table 2: Distribution of study participants according to last visit to dentist

\begin{tabular}{lll}
\hline Visit to dentist & Rural (\%) & Urban (\%) \\
\hline Within the last year & $118(23.6)$ & $137(27.4)$ \\
Within 2 years & $112(22.4)^{*}$ & $72(14.4)$ \\
Within 5 years & $97(19.4)^{*}$ & $69(13.8)$ \\
Never & $173(34.6)$ & $222(44.4)^{*}$ \\
Total & $500(100)$ & $500(100)$ \\
\hline
\end{tabular}

${ }^{*} p<0.05$ significant

Table 3: Distribution of study participants according to dentition status

\begin{tabular}{lll}
\hline Dentition status & Rural (\%) & Urban (\%) \\
\hline Excellent & $73(14.6)$ & $77(15.4)$ \\
Very good & $178(35.6)$ & $162(32.4)$ \\
Good & $156(31.2)$ & $154(30.8)$ \\
Fair & $78(15.6)$ & $78(15.6)$ \\
Poor & $15(3.0)$ & $29(5.8)^{*}$ \\
Total & $500(100)$ & $500(100)$ \\
\hline
\end{tabular}

${ }^{*} p<0.05$ significant 
Table 4: Mean and standard deviation of OHIP and REALD score among study participants

\begin{tabular}{lllrll}
\hline & Rural/urban & $N$ & Mean & $\begin{array}{l}\text { Std. } \\
\text { deviation }\end{array}$ & p value \\
\hline OHIP & Rural & 500 & 6.46 & 6.81 & 0.002 \\
& Urban & 500 & 6.34 & 8.49 & \\
\multirow{2}{*}{ REALD-30 } & Rural & 500 & 12.88 & 7.21 & 0.000 \\
& Urban & 500 & 20.89 & 7.33 & \\
\hline
\end{tabular}

Table 5: Correlation of study participants according to OHIP and REALD score

\begin{tabular}{lllll}
\hline Variable & & Rural/urban & OHIP & REALD-30 \\
\hline REALD-30 & $\begin{array}{l}\text { Pearson } \\
\text { correlation }\end{array}$ & $0.483^{*}$ & $-0.088^{*}$ & 1 \\
& $\begin{array}{l}\text { Sig. } \\
(2 \text {-tailed) }\end{array}$ & 0.000 & 0.005 & - \\
& $N$ & 1,000 & 1,000 & 1,000 \\
\hline
\end{tabular}

${ }^{*} p<0.00$ highly significant

\section{Discussion}

The aim of this study is to assess the oral health literacy among the rural and urban population and to correlate the OHRQoL with the level of oral health literacy. The present study's work believes that oral health literacy is an integral part of general health and can be positively correlated to oral health outcomes like a change of dental health status and OHRQoL. In addition, there is an urgent need for an oral health instrument that is related to dental health literacy. It has been observed by various authors that patients get exposed to different types of treatment procedure throughout their lifetime which leads to a change in medical and dental literacy level. ${ }^{16,17}$
It has been reported in the literature that different dental service utilization patterns like patients' last visit to a dentist for any problem have also been linked with poor OHRQoL. ${ }^{12,18}$ In the present study, 34 (27.4\%) of urban participants visited the dentist every year and 72 (14.4\%) visited every 2 years which was in contrast to the study done by Aruna Devi et al., ${ }^{17}$ where $18.6 \%$ of participants visited the dentist every year and $5.4 \%$ visited every 2-3 years, which shows that the participants in the present study are less aware or less motivated toward dental diseases. It should be mandatory for the clinician to know the level of health literacy that a patient possesses before giving any health instructions. But the majority of dental practitioners did not know about the fact that patient could not read and interpret the scientific material related to treatment. ${ }^{16,18}$

The present study marks an attempt for identifying patients with low dental health literacy by using a word recognition instrument. A valid and reliable dental health literacy instrument (REALD-30) have a great potential to assist in the investigation of the relationship among low dental health literacy, health inequalities, and need for improvement of dental health care outcomes. The mean score of REALD-30 in rural was $12.88 \pm 7.214$ which was in contrast to the study done by Lee et al. ${ }^{19}$ While the urban REALD30 score in the present study was found to be slightly higher $(20.9 \pm 7.334)$ compared with the study done by Aruna Devi et al. ${ }^{17}$ for urban population $(16.3 \pm 6.27)$.

There are various factors like disease status, demographic characteristics, and environment that could affect the measures of OHRQoL, the OHIP-14 rating score. But the health perception is a major domain of all possible determinants of OHRQoL. Therefore, the OHIP-14 could be a good variable for testing the predictive validity of the oral health literacy score. In the present study, OHIP was used to provide a more comprehensive measure than

Table 6: Distribution of study participants' response according to the mean OHIP (OHIP-14)

\begin{tabular}{|c|c|c|c|}
\hline Parameter & Questions & Rural & Urban \\
\hline \multirow[t]{2}{*}{$\begin{array}{l}\text { Functional } \\
\text { limitation }\end{array}$} & $\begin{array}{l}\text { Have you had trouble pronouncing any words because of problems with your teeth, mouth, or } \\
\text { dentures? }\end{array}$ & $0.45 \pm 0.96$ & $0.43 \pm 0.90$ \\
\hline & $\begin{array}{l}\text { Have you felt that your sense of taste has worsened because of problems with your teeth, mouth, } \\
\text { or dentures }\end{array}$ & $0.50 \pm 0.96$ & $0.47 \pm 0.95$ \\
\hline \multirow[t]{2}{*}{ Physical pain } & Have you had painful aching in your mouth? & $0.73 \pm 01.08$ & $0.83 \pm 1.15$ \\
\hline & $\begin{array}{l}\text { Have you found it uncomfortable to eat any foods because of problems with your teeth, mouth, } \\
\text { or dentures? }\end{array}$ & $0.70 \pm 1.09$ & $0.80 \pm 1.16$ \\
\hline \multirow{2}{*}{$\begin{array}{l}\text { Psychological } \\
\text { discomfort }\end{array}$} & Have you been self-conscious because of your teeth, mouth, or dentures? & $0.45 \pm 0.97$ & $0.60 \pm 1.09$ \\
\hline & Have you felt tense because of problems with your teeth, mouth, or dentures? & $0.49 \pm 0.98$ & $0.46 \pm 0.94$ \\
\hline \multirow{2}{*}{$\begin{array}{l}\text { Physical } \\
\text { disability }\end{array}$} & Has your diet been unsatisfactory because of problems with your teeth, mouth, or dentures? & $0.51 \pm 0.97$ & $0.53 \pm 1.01$ \\
\hline & Have you had to interrupt meals because of problems with your teeth, mouth, or dentures? & $0.48 \pm 0.95$ & $0.48 \pm 0.98$ \\
\hline \multirow[t]{2}{*}{$\begin{array}{l}\text { Psychological } \\
\text { disability }\end{array}$} & $\begin{array}{l}\text { Have you found it difficult to relax because of problems with your teeth, disability mouth, } \\
\text { or dentures? }\end{array}$ & $0.46 \pm 0.94$ & $0.37 \pm 0.85$ \\
\hline & Have you been a bit embarrassed because of problems with your teeth, mouth, or dentures? & $0.37 \pm 0.86$ & $0.26 \pm 0.67$ \\
\hline \multirow[t]{2}{*}{$\begin{array}{l}\text { Social } \\
\text { disability }\end{array}$} & $\begin{array}{l}\text { Have you been a bit irritable with other people because of problems with your teeth, mouth, or } \\
\text { dentures? }\end{array}$ & $0.36 \pm 0.84$ & $0.29 \pm 0.78$ \\
\hline & $\begin{array}{l}\text { Have you had difficulty in doing your usual jobs because of problems with your teeth, mouth or } \\
\text { dentures? }\end{array}$ & $0.43 \pm 0.94$ & $0.25 \pm 0.76$ \\
\hline \multirow[t]{2}{*}{ Handicap } & $\begin{array}{l}\text { Have you felt that life in general was less satisfying because of problems with your teeth, mouth or } \\
\text { dentures? }\end{array}$ & $0.32 \pm 0.82$ & $0.31 \pm 0.85$ \\
\hline & Have you been totally unable to function because of problems with your teeth, mouth, or dentures? & $0.21 \pm 0.71$ & $0.27 \pm 0.85$ \\
\hline Total & & $6.46 \pm 6.81$ & $6.34 \pm 8.4$ \\
\hline
\end{tabular}


self-perceived oral health status. The mean score of OHIP in the present study for rural was $6.46 \pm 6.815$ which cannot be correlated due to lack of literature on rural population, whereas the score of OHIP in urban was found to be $6.34 \pm 8.492$ which was in contrast with the study done by Richman et al., ${ }^{12}$ where the mean OHIP score was 4 with a range of $0-14$. And, with the study done by Aruna Devi et al., ${ }^{17}$ the mean OHIP-14 score was $1.23 \pm 1.89$.

\section{LiMITATIONS}

The present study has used the REALD-30 which is a reading recognition test method and can be used for basic dental health literacy and it does not test the functional use of health literacy. There is a need to investigate the other methods of assessing oral health literacy along with the REALD 30 and check the effectiveness of each method.

\section{CONCLUSION}

This study focuses on the effect of poor health literacy on patients' OHRQoL. The present study showed that abstract knowledge about oral health is significantly less among low literacy participants which ultimately affected their quality of life and treatment outcomes. It can be concluded that due to low health literacy, the patient would have less knowledge about their oral and medical conditions which may increase the total burden of disease.

\section{Clinical Significance}

The present study finding suggests the marked discrepancy of oral health literacy among the rural and urban population, which affects the utilization of health care services. With these findings, an effective educational program can be implemented to improve the underutilization of oral health care in rural and urban population.

\section{References}

1. Ratzan SC, Parker RM. Introduction. In: Selden CR, Zorn M, Ratzan SC, Parker RM. ed. National Library of Medicine current bibliographies in medicine: health literacy. NLM Publ. No. CBM 2000-1. Bethesda, MD: National Institutes of Health, 2000; pp. 5-8.

2. Roter DL. Studiesof doctor-patient interaction. Annu Rev Public Health 1989;10:163-180. DOI: 10.1146/annurev.pu.10.050189. 001115.

3. Ong $L$, Haes JD, et al. Doctor-patient communication: a review of the literature. Soc Sci Med 1995;40:903-918. DOI: 10.1016/02779536(94)00155-M.
4. Mayeaux EJ Jr, Murphy PW, et al. Improving patient education for patients with low literacy skills. Am Fam Physician 1996;53(1):205-211.

5. Bohlman LN, Panzer AL, et al. Health literacy: a prescription to end confusion. Institute of Medicine. 2004. Accessed online 24.1.2019, at: http://www.iom.edu/report.asp?id=19723.

6. Kirsch I, Jungeblut A, et al. Adult literacy in America: a first look at the results of the National Adult Literacy Survey. Washington (DC): National Center for Education Statistics, US Department of Education, 1993.

7. Horowitz AM, Kleinman DV. Oral health literacy: the new imperative to better oral health. Dent Clin North Am 2008;52:333-344. DOI: 10.1016/j.cden.2007.12.001.

8. Rudd R, Moeykens B, et al. Health and literacy: a review of medical and public health literature. Annual Review of Adult Learning and Literacy 1998;1(5):1-37.

9. Sabbahi DA, Lawrence HP. Development and evaluation of an oral health literacy instrument for adults. Comm Dent Oral Epidemiol 2009;37:451-462. DOI: 10.1111/j.1600-0528.2009.00490.x.

10. Safeer RS, Keenan J. Health Literacy: The Gap Between Physicians and Patients. Am Fam Physician 2005;72(3):463-468.

11. Lee JY, Rozier RG, et al. Development of a Word Recognition Instrument to Test Health Literacy in Dentistry: The REALD-30 A Brief Communication. J Public Health Dent 2007;67(2):94-98. DOI: 10.1111/j.1752-7325.2007.00021.x.

12. Richman JA, Lee JY, et al. Evaluation of a word recognition instrument to test health literacy in Dentistry: The REALD-99. J Public Health Dent 2007;67(2):99-104. DOI: 10.1111/j.1752-7325.2007.00022.x.

13. Gong DA, Lee JY, et al. Development and testing of Functional Health Literacy in Dentistry (TOFHLiD). J Public Health Dent 2007;67(2):105112. DOI: $10.1111 /$ j.1752-7325.2007.00023.x.

14. U.S. Department of Health and Human Services, National Institutes of Health, National Institute of Dental and Craniofacial Research. The invisible barrier: literacy and its relationship with oral health. A report of the workgroup sponsored by the National Institute of Dental and Craniofacial Research, National Institutes of Health, U.S. Public Health Service, Department of Health and Human Services. J Public Health Dent 2005;65(3):174-182.

15. Davis TC, Michielutte $R$, et al. Practical assessment of adult literacy in health care. Health Educ Behav 1998;25:613-624. DOI: 10.1177/109019819802500508.

16. Parker RM, Baker DW, et al. The Test of Functional Health Literacy in Adults: a new instrument for measuring patients' literacy skills. J Gen Intern Med 1995;10:537-541. DOI: 10.1007/BF02640361.

17. Aruna Devi M, Sugandhi S, et al. Reliability and Validity of a Questionnaire to assess Oral Health Literacy among College Students in Bengaluru City. Int J Contemp Dent Pract March 2011;2(2):43-47.

18. Slade GD. Derivation and validation of a short-form oral health impact profile. Community Dent Oral Epidemiology 1997;25:284-290. DOI: 10.1111/j.1600-0528.1997.tb00941.x.

19. Lee JY, Rozier RG, et al. Development of a world recognition instrument to test health literacy in dentistry: The REALD-30-A brief communication. J Public Health Dent 2007;67:94-98. DOI: 10.1111/j.1752-7325.2007.00021.x. 